\title{
Tourism e-services and Jewish heritage: a case study of Prague
}

DOI 10.1515/ejthr-2016-0022

received 10 November, 2016; accepted 30 September, 2016

\begin{abstract}
Our paper describes the new potential for tourism e-services (smartphone apps and enhanced Internet platforms) for promoting the intangible cultural heritage in European destinations using the example of Prague's Jewish heritage. Although quite a few tourism e-services are present in the tourism market in Prague, their full potential has not been exhausted.
\end{abstract}

The paper shows that one of the ways how the intangible cultural heritage in European destinations can be promoted is through employing the apps for smartphones and tablets involving local myths and legends constituting the backbone of local cultural and religious traditions.

Our research is based on the empirical results of the three stages of our own questionnaire survey conducted in Prague in May-August 2013 for assessing the revealed preferences of Prague's residents and tourists for such apps and novel IT solutions.

Our results demonstrate that a potential app should feature a narrative, a possibility to upload additional information, as well as interactive online maps. The app should be offered at both App Store and Android Market Play free of charge with embedded in-app purchases that might reach up to 3 EUR in additional payments.

The paper tackles a top-notch field of electronic tourism (or e-tourism) that embeds the mobile technologies and

\footnotetext{
*Corresponding author: Wadim Strielkowski, University of Cambridge, Judge Business School, United Kingdom, E-mail: w.strielkowski@jbs.cam.ac.uk

Nicole Mitsche, University of Sunderland, Faculty of Business and Law, St Peter's Way, Sunderland, SR6 ODD, United Kingdom
}

the intangible cultural heritage approach. The results and outcomes might be useful not only for IT developers specialising in digital tourism but also for local stakeholders and residents.

Keywords: Cultural heritage; E-tourism; Information technologies; Consumer preferences

Acknowledgements: The authors would like to thank Michal Vokoun, Ondřej Kolek, Stefana Arabadjieva, and Tomáš Vaverka, students of the Department of Marketing Communication and PR of the Charles University in Prague, for their help with collecting the data for this project.

\section{Introduction}

Cultural tourism represents one of the largest key industries of the 21st century both in Europe and worldwide. It is also one of the forms of tourism that is expected to yield significant growth in the future $[4,6,15,16,26,30,36]$.

In the beginning, cultural tourism constituted an alternative form of tourism being an antidote to the mass tourism represented by the package holidays. Starting from the 1990s, the cultural tourism started to be targeted at the integration of production and consumption, as well as on deepening and increasing the ties between suppliers and consumers [17].

However, major changes have taken place in the tourism industry since the 1990s and in 2000s, and this greatly impacted the way cultural tourism is going to develop in the forthcoming decades [3,7,18,37]. In general, there is a shift from the traditional to the novel way of experiencing cultural resources. Moreover, there is also an increasing trend of proactive involvement of cultural tourists into understanding the tourism destination in a

(cc) BY-NC-ND (c) 2016 Nicole Mitsche, Wadim Strielkowski, published by De Gruyter Open

This work is licensed under the Creative Commons Attribution-NonCommercial-NoDerivs 3.0 License. 
better and more holistic way (e.g. via active interaction, participation, or taking part in quests, games, sport events or sightseeing guided tours). These changes are largely based on employing a major fusion of information and communication technologies (ICT), as well as the new services (e-services) that bring to the picture various modern information technologies $[5,19,27,35]$. Then, there exists a certain demand on the tourism market to assess the preferences of potential tourists for innovative and novel e-services that might enhance their experience before, during, and after a visit to the cultural destination of their choice. This assessment could provide policy-makers with important insights to help them appropriately shape the supply side of the tourism market in order to respond to the latent demand whilst developing sustainable cultural tourism strategies.

Rasinger et al [25] describe how mobile services are gradually supplementing traditional information sources in tourism experience: tourist can access information before, during, or after the visit, be able to obtain updates while on site and are no longer tied to the traditional sources of information, such as guidebooks, travel guides, or paper maps. Moreover, the widespread of smartphones that followed the introduction of the first Apple's smartphone in 2007, enabled tourists to be permanently connected to the Internet and to access information via various apps. Another very important aspect of technical innovations in cultural tourism is related to its gamification principle, which is very important for the pro-active approach of the new cultural tourists [28]. Gamification that enables to get to know cultural tourism destinations in a better enhanced way might include interactive games, quests, or geocaching that combine a guided tour of the sights with an interesting adventure [22].

Our paper describes the new potential of tourism e-services (smartphone apps and enhanced Internet platforms) for promoting the intangible cultural heritage in European destinations using the example of Prague's Jewish heritage. It appears that one of the ways how this can be achieved is through the apps for smartphones and tablets involving local myths and legends constituting the backbone of local cultural and religious traditions.

The paper is organised as follows: Section 2 describes cultural tourism in Europe mainly concentrating on the European cities. Section 3 focuses on the role of modern technologies in enhancing tourism supply and provides several examples from European cultural cities. Section 4 describes the methodology of the own survey questionnaire including the data collection process and data analysis. Section 5 reports the results of data analysis and outlines the main obtained results. Finally, section 6 concludes with overall conclusions and policy implications.

\section{Cultural tourism in Europe}

Sustainable cultural tourism strategies have the potential to assist the conservation of local identities embedded in their respective cultural heritage, while supporting economic growth [8]. The economic impact that cultural tourism has on regional development is quite appealing to policy-makers, whose aim is to maximise the potential intake [2].

In Europe, similar to the other parts of the world, cultural tourism is concentrated in European cities that can boast splendour, 'genius loci', charm, as well as a plethora of cultural heritage, both tangible (representing e.g. buildings, sites, museums, monuments, and palaces) and intangible (local customs and traditions, festivals, fairs, stories and legends).

Table 1 that follows reports top European destination cities by the number of visitors and spending. One can see that traditional 'hubs' like London and Paris generate almost twice as much visitors as Barcelona, Amsterdam or Rome. Prague, the city which serves as a case study for our research reported in the next sections of this paper, occupies the 9th position in Europe and 19th in the world [21].

European destinations aim at better developing their supply side in order to increase their economic competitiveness. For instance, Herget et al. [13] show which factors contribute to the success of European small and medium enterprises (SMEs) in the field of tourism. Innovativeness

Table 1: Top European destination cities by the number of visitors and spending

\begin{tabular}{lll}
\hline City & $\begin{array}{l}\text { Number of visitors } \\
\text { (in millions) }\end{array}$ & $\begin{array}{l}\text { International visitor spending } \\
\text { per city resident (in \$) }\end{array}$ \\
\hline London & 18.82 & 2480 \\
Paris & 16.06 & 1385 \\
Istanbul & 12.56 & 674 \\
Barcelona & 7.63 & 2793 \\
Amsterdam & 7.44 & 1333 \\
Rome & 7.41 & 944 \\
Milan & 7.17 & 493 \\
Vienna & 5.81 & 841 \\
Prague & 5.47 & 1501 \\
\hline
\end{tabular}

Source: [12] 
and the use of modern technologies to attract more tourists and to increase the intensity of their tourism experience are one of them.

Table 2 reports the statistics on the number of nights spent in European most popular tourist regions with the split of the region's share and the share in national total. It is remarkable to observe that cities like London, Prague or Budapest have about 50\% in the total national share, with other popular cities like Berlin or Venice, also playing a considerable role. These numbers only strengthen the debate from the previous sections on the role of cities as cultural tourism hubs in Europe.

Furthermore, it can be shown using the example of incoming tourism in Prague (see Table 3) that while some groups of tourists are declining, others are growing. For instance, the current trends in the Czech Republic and in Prague is that while the number of Russian tourists is declining due to the economic downfall in Russia and the sanctions imposed on the Russian economy, the vacant places are taken by the Chinese tourists that are growing in numbers [10]. Then, there is a necessity to adjust the supply of cultural heritage tourism-related content to the new emerging group of consumers (tourists).

Nevertheless, the role that e-services can play in shaping the demand side has thus far not been fully explored. Strielkowski et al. [32] discuss the role of e-services in shaping up the digital cultural heritage offer in European cultural destinations (represented by Amsterdam, Genoa and Leipzig). Moreover, Strielkowski [31] describes the results of the focus groups that were held in Prague with an aim to construct a blueprint for the mobile app (provisionally called 'Golem'), which would aim at exploiting local myths and legends (or mysteries and thrillers) in order to capture the new segment of the tourism market - e.g. the young and adventurous tourist who might be interested in exploring the Prague's cultural heritage in a new, unknown way, to play city games or conduct "treasure hunts", etc.

Putting Prague aside, one can find more examples of using new (e.g. mobile) technologies in enhancing the cultural heritage in various destinations around the world. For example, Eriksson and Strandvik [11] report the results of a study conducted on Åland Islands in Finland that attempted to find out the determinants of demand for the tourism mobile applications, while Liu and Li [20] describe the results of a study from China that focused on mobile gaming applications. Both studies have several things in common: namely, it is very important to focus on the context of the games or services, then the cultural tourism destination represents the key element in all technology applications.
Table 2: Nights spent in European most popular tourist regions

\begin{tabular}{|c|c|c|c|}
\hline & $\begin{array}{l}\text { Total nights } \\
\text { spent (millions) }\end{array}$ & $\begin{array}{l}\text { Most popular } \\
\text { region }\end{array}$ & $\begin{array}{l}\text { Share in } \\
\text { national total } \\
(\%)\end{array}$ \\
\hline \multicolumn{4}{|c|}{ Countries where all regions are coastal } \\
\hline Denmark & 10.6 & Hovedstaden & 51.0 \\
\hline Estonia & 3.9 & & - \\
\hline Ireland & 11.3 & $\begin{array}{l}\text { Southern and } \\
\text { Eastern }\end{array}$ & 75.7 \\
\hline Cyprus & 12.9 & & - \\
\hline Latvia & 2.9 & & - \\
\hline Lithuania & 3.0 & & - \\
\hline Malta & 8.4 & & - \\
\hline Portugal & 35.6 & Algarve & 37.4 \\
\hline Finland & 5.7 & Helsinki & 41.1 \\
\hline Sweden & 12.3 & Stockholm & 32.2 \\
\hline \multicolumn{4}{|c|}{ Countries with coastal and non-coastal regions } \\
\hline Belgium & 16.5 & $\begin{array}{l}\text { Région de } \\
\text { Bruxelles- } \\
\text { Capitale }\end{array}$ & 30.6 \\
\hline Bulgaria & 14.1 & Yugoiztochen & 46.7 \\
\hline Germany & 74.8 & Berlin & 16.7 \\
\hline Greece & 74.7 & Kriti & 28.9 \\
\hline Spain & 259.6 & Canarias & 32.0 \\
\hline France & 130.9 & Île de France & 34.3 \\
\hline Croatia & 61.1 & $\begin{array}{l}\text { Jadranska } \\
\text { Hrvatska }\end{array}$ & 96.9 \\
\hline Italy & 186.8 & Veneto & 22.1 \\
\hline Netherlands & 34.4 & Noord-Holland & 44.5 \\
\hline Poland & 13.0 & Matopolskie & 21.9 \\
\hline Romania & 3.8 & Bucuresti & 40.9 \\
\hline Slovenia & 6.0 & $\begin{array}{l}\text { Zahodna } \\
\text { Slovenija }\end{array}$ & 68.6 \\
\hline United Kingdom & 105.5 & London & 47.4 \\
\hline Norway & 8.5 & Oslo & 26.5 \\
\hline \multicolumn{4}{|c|}{ Landlocked countries } \\
\hline Czech Republic & 22.1 & Praha & 60.5 \\
\hline Luxembourg & 2.5 & & - \\
\hline Hungary & 12.4 & $\begin{array}{l}\text { Közép- } \\
\text { Magyarország }\end{array}$ & 60.3 \\
\hline Austria & 78.1 & Tirol & 40.0 \\
\hline Slovakia & 3.9 & Bratislavský kraj & j 27.5 \\
\hline
\end{tabular}

Source: [12] 
Table 3: Tourists in Prague in accommodation facilities (by the country of origin)

\begin{tabular}{llllll}
\hline Country & Guests & Overnight stays & $\begin{array}{l}\text { Average number of } \\
\text { overnight stays }\end{array}$ & $\begin{array}{l}\text { Overall increase in the \% increase in the } \\
\text { number of guests } \\
\text { number of guests }\end{array}$ \\
\hline Guests, total & $1,476.831$ & $3,654.670$ & 2.5 & -20.672 & $-1,4$ \\
Residents & 187.560 & 338.864 & 1.8 & 10512 & 5,9 \\
Non-residents & $1,289.271$ & $3,315.806$ & 2.6 & -31184 & -2.4 \\
Germany & 169.312 & 400.135 & 2.4 & -22203 & -11.6 \\
Russia & 132.229 & 554.506 & 4.2 & 8276 & 6.7 \\
USA & 102.147 & 251.673 & 2.5 & -1807 & -1.7 \\
United Kingdom & 77.595 & 183.629 & 2.4 & 1768 & -7714 \\
Italy & 73.720 & 207.279 & 2.8 & & -9.5 \\
\hline
\end{tabular}

Source: CZSO [9]

Overall, it can be seen that the potentials for cultural tourism in European cultural destinations is enormous and new paths should be found to develop its hidden and embedded layers. There are many realms of cultural tourism with the most promising being the employment of the intangible cultural heritage.

\section{The role of IT solutions in enhancing tourism supply}

Overall, one can state that the role of IT solutions in fostering tourism supply is crucial. Although personal computers became probably the most important must-have item in the 1990s, the 2000s and the 2010s belong to the smartphones and (most recently) handhelds or tablets (with those two becoming one symbiotic device). Since the appearance of an iPhone, a revolutionary cellular phone with a touchscreen that combined the features of a mobile phone and a portable computer, smartphones gained wide popularity and are currently owned by the majority of world's population [1]. While most of Apple devices were relatively expensive and therefore unavailable for the larger masses, the introduction of Android-based devices by Google made smartphones and tables widely available to the people from virtually all income groups.

Smartphones and smartphone-based solutions represents perhaps the most interesting way to exploit fright mystery and thriller tourism in European destinations and to attract young European, the notorious users of smartphones, to knowing their cities better. An example of how this might be done are the smartphone apps offered either by Apple Store or Google Market Play: for example, 'Dexter's Disciples' or 'Chasing Salander' by
Norsteds (the publisher of Stieg Larsson's books). The latter application represents an extension of the original story from the book, complimented by the new facts and details from the world of the 'Girl with the Dragon Tattoo'. Stockholm Stadsmuseum also understood the potential of the 'Millennium Trilogy' launching its 'Stieg Larsson Millennium Tour' (both guided tour or a map with a selfguided tour are available). Combining a quest and a game, the tour re-tells the story of Stockholm, introducing its various parts and neighbourhoods, using the scenes and parts from 'Millennium Trilogy'.

A very cheap but nevertheless an effective way how to promote mystery and thriller tourism in European cities might be through a game-like app based in a cultural destination that would involve local myths and legends and blend them with popular culture. This app might constitute quest-like games often played by teenagers and adults in urban locations (known as 'treasure hunts') bearing the elements of the legends and the stories, narratives of the city's most interesting parts and neighbourhoods as well as including the interactive element of 'being a part of the city'. As far as the interactivity is concerned, the app should also include a contest-like element of multiple users playing against each other in real time, or competing for a prize or some incentive, thus resembling the 'urban games' or 'urban quests' that are often organised by the local residents in large cities and include elements of treasure hunt and gaming [31].

It was decided to attempt to develop a blueprint for such an app that can be used in order to get to know Prague's Jewish heritage. Through the feedback obtained in focus groups, it was clear that the most famous aspect of Prague's Jewish heritage is the legend of Golem.

Golem is often associated not only with Prague's Jewish heritage but also with Prague itself [38] and it 
found its way into many Czech popular films and cartoons, as well as into mystery and thriller literature [23]. It is also often a popular name for restaurants and cafés in the Czech capital. According to Idel [14], in Jewish mythology, Golem resembles an animated anthropomorphic entity created entirely from inanimate matter (e.g. sand, clay, etc.). Although there are several legends featuring Golem that took place in various parts of Europe, perhaps the most famous legend involves Judah Loew ben Bezalel, the 16th century Chief Rabbi of Prague and the famous Cabbalist of his day who allegedly created the Golem to defend the Prague ghetto and the local Jewish community [29]. Rabbi Loew constructed the Golem out of clay from the banks of the Vltava (Moldau) river and brought it to life through rituals and Hebrew incantations (in some versions by inscribing the word 'emet' ('truth' or 'reality') in Hebrew on Golem's forehead or by inserting the small table with incantations into the slot on Golem's forehead). The Golem helped Prague's Jews and carried out difficult tasks for Rabbi Loewe, until one day it became increasingly violent, killing people and causing rampage all around the city. Rabbi Loew had to destroy Golem and what remained of it, was stored in the attic of the Old New Synagogue where, as some legends have it, it can be found nowadays.

The tourists and the local residents alike would be able to stroll around the narrow streets of the Prague's Jewish Quarter while learning the legend of Golem and other themed legends and stories while experiencing the atmosphere of locations mentioned in the legends of the Jewish Prague.

\section{Survey methodology}

In order to complete the objectives described in the introduction of this paper, we designed, piloted and implemented our own survey questionnaire in Prague. We employed the questionnaire development methodology described for instance in Vernon, Van Leeuwen and Nijkamp or in Chiabai et al. [8,33,34].

Our questionnaire was developed based on the results of the in-depth interviews and small focus groups held in Prague in the spring of 2014. All data collection was done by a group of students specially trained for data collection techniques. The students carefully recorded each interview and added detailed description of the respondents whenever personal information was provided.

When it comes to the survey questionnaires, it is typical for the data samples that there emerge limitations related to the sample selection, size, geographical distribution, etc. On the other hand, primary and unique data resulting from the survey have an advantage against statistical data collected at the macro level.

The respondents for our sample were selected by the stratified semi-random sampling. At first, the research team randomly selected districts of Prague Old Town for conducting interviews, and then randomly selected sites within these districts. Then, the interviewers randomly targeted locations and approached every third visitor leaving the tourist site (a museum, a restaurant, a synagogue, etc.). Although limited in scope, the obtained data sample seemed to be robust and could be analysed in order to determine the basic existing patterns and factors of mobile technologies used for better understating of the Prague Jewish heritage.

The questionnaire was designed in such a way that it can be completed during a maximum time of five minutes. We understand and respect the tourists who visited Prague for only a few days being on a tight schedule and often have a fixed program of the visit they want to keep. For this reason, we did not want to force respondents to make a greater investment of time and put in the questionnaire only absolutely key issues that constituted the scope of our research.

The sample size of respondents was set at 240 . The response rate was $72.50 \%$. Respondents were selected from all age groups, and different nationalities.

The number of questions in the questionnaire was set at 16, but after detailed consideration, two questions had to be omitted. The final number of questions was therefore 14. The questionnaire contained a combination of openended and closed questions, the majority of responses in closed issues and it is limited to two options (Yes or No). Open-ended questions pursue qualitative values, but are structured so as not to require long and extensive openended answers. We envisaged that the time of the respondents was limited and therefore aimed at getting quick and concise answers from them.

The questions in our questionnaire were divided into three blocks. The first block is the initial question mapping socio-demographic aspects of the respondents. They allow us to obtain an overview of the interviewees sample in terms of age, national origin or sex. The second block addressed the issue of tourist habits of the respondents. We were interested in the extent to which respondents used e-services in tourism during their travels and what specific services in the area of e-services were popular among them. These questions served primarily as market research for the possible development of applications targeted at tourists seeking to explore the Jewish heritage in 
Prague. The full version of the questionnaire is presented in the appendix to this paper.

The results of the questionnaire were analysed using several statistical techniques: calculating the means and averages as well as analysing the data using correlation analysis and regression techniques. However, for the scope of this paper, we only report the descriptive statistics that stems from the questionnaire surveys.

The results of the questionnaire survey allowed us to provide a realistic view of what the requirements tourists using e-services related to Prague's Jewish heritage might have. Moreover, the third and final part of the questionnaire charted the awareness of the Jewish monuments amongst respondents as well as their opinion of their presentation and the quality of services associated with Prague's Jewish heritage.

The results obtained from our research are essential for optimising the potential smartphone applications related to Prague's Jewish heritage and its representations, its design and content, as well as its price, the mode of delivery and the payment vehicle (the way the monetisation should be designed, devised, structured and executed in order to allow making a profit).

\section{Main results and discussions}

The age of the respondents was spread over the variance of 20-69 years (the mean age was 33.4 years). Gender representation of the interviewed respondents yielded almost an equilibrium conditions with the spread being nearly identical (51\% males and 49\% females).

There was a noted significant difference in the composition of the audience. Table 4 demonstrates the distribution of respondents by nationality (the largest group were the French, citizens of the USA, as well as the visitors from the UK) (Table 4).

In order to understand the profile of the visitors with interest in Jewish heritage and sites in Prague and the possibility for creating the most effective range of services associated with this type of tourism, the following observations proved to be absolutely crucial: first, we examined how preparations for visiting Jewish heritage in Prague actually worked. The results show that the the most popular online medium was Trip Advisor, which was mentioned by more than a quarter of respondents. In addition, among the most frequently used tools were online maps, Booking.com tourist guide, as well as Yelp and some Czech tourist websites.
Another key finding stemming from our own data collection was the information that $95 \%$ of respondents (across the aforementioned age spectrum) owned a smartphone (or a handheld device) and $68 \%$ of them frequently downloaded tourist applications. Our data provide us with a possibility to identify tourists' demand for tourist mobile applications, although it came as a surprise that even though many respondents declared that they preferred free apps, the overall majority of respondents were willing to pay for the tourism mobile applications.

In order to find out about the most optimal offer of a mobile tourism app for the visitors of Jewish heritage monuments in Prague, in the last part of our research, we focused on a specific issue with Jewish tourists' sights. The issue was the following: When asked to name examples of Prague Jewish heritage, the majority of our respondents remembered primarily Jewish cemetery and the synagogues, and approximately seven people mentioned the Jewish quarter (Table 5).

Overall, most of our respondents were satisfied with the range of Jewish Heritage in Prague and its quality of services, as evidenced by the average score of 7.5 out of

Table 4: Respondents by country (in \%)

\begin{tabular}{ll}
\hline Nationality & Share in \% \\
\hline France & 25 \\
USA & 17 \\
UK & 14 \\
Germany & 12 \\
Poland & 10 \\
Israel & 6 \\
Netherlands & 5 \\
Italy & 4 \\
Russia & 4 \\
Korea & 3 \\
\hline
\end{tabular}

Source: Own results

Table 5: Top Jewish heritage sites in Prague

\begin{tabular}{ll}
\hline Jewish heritage site & Share in \% \\
\hline Prague's Jewish cemetery & 60 \\
Synagogues & 25 \\
Jewish Museum & 13 \\
Jewish Quarter & 7 \\
\hline
\end{tabular}

Source: Own results 
40 entries with a span of 1- 10, when the value of 10 was to mark the highest satisfaction. Conversely, among the most frequently mentioned complaints related to Prague Jewish heritage sites, were the lack of information in the vicinity of Jewish sites, lack of audio and video materials, relatively high price of admission and hiring tour guides, absence of free guides and the poor condition of the Prague's Jewish cemetery.

When it comes to the price and the payment vehicle for the potential tourism mobile application, the results came through as follows (see Table 6).

Overall, when looking at the results reported in Table 6 , it appears that the majority of the respondents preferred a Prague's Jewish Heritage-themed app that would be able for download free of charge but might include in-app purchases that might constitute about 3 EUR in total. While the majority of respondents prefer a free app and a free download, it seems that most of the customers understand that each app has its price and should yield a profit for its developers.

\section{Conclusions and policy implications}

Our research was conducted with the help of qualitative and quantitative methods, which sought to uncover the experience of foreign tourists from different countries with the presentation of Jewish heritage in Prague. We aimed at clarifying the preferences of respondents visiting the Jewish sites and monuments in the capital city of the Czech Republic, with the special stress on tourism mobile applications. The results obtained from our questionnaire survey yielded some interesting findings, which can be used in the actual design and development of functioning tourism mobile applications that would help the tourists interested in Jewish cultural heritage in Prague to get

Table 6: Potential price for Jewish Heritage app (answers in \%)

\begin{tabular}{ll}
\hline Price (in EUR) & Share in $\%$ \\
\hline 0 EUR & 45 \\
$0.1-1$ EUR & 18 \\
$1-3$ EUR & 27 \\
$3.1-5$ EUR & 4 \\
$>5$ EUR & 6 \\
\hline
\end{tabular}

Source: Own results to know it better and to experience it in a more deep and enhanced way.

According to our respondents, the existing IT solutions such as Trip Advisor website, online maps, Booking. com or Yelp proved to be the most popular and helpful in getting to know the city in a better and more profound way. Our results therefore indicate that potential tourism mobile applications should contain user-friendly features that are to be found in the tourism-related websites. These features might or should include the ranking of the visited places, the high-quality online maps, the availability of businesses and services around Prague's Jewish heritage as well as the users 'reviews.

When it comes to determining the appropriate price for a mobile app, our questionnaire survey pointed out at the fact that although the largest group of our respondents preferred free apps, the overall majority of the respondents declared their willingness to pay for the mobile application. It would therefore be possible in case a creation of an actual application is envisaged, for example, to offer a free (light) version and then the expanded version, for which the users would have to pay something extra (perhaps in a form of in-app purchases).

Furthermore, our research results show that in terms of monuments, those belonging to the "top of the top" locations mentioned by our respondents are represented by the Jewish cemetery and synagogues in Prague's Jewish quarter. It would therefore be potentially useful to create a mobile application that would include these and other sights and narratives associated with them embedding the area of Jewish Heritage in Prague in order to widen the awareness and to increase the attractiveness for others than the above mentioned Jewish quarter locations.

Finally, our questionnaire survey enabled us to determine the demand for information on individual monuments, tourist routes and audio and video materials associated with a tour of Prague Jewish sites. More than one-third of our respondents told us that they did not use the services of an actual human tour guide, which points out at the possibility of introducing mobile applications and personal audio tours of the Prague Jewish sights. Inspiration in this case would be based, for example, on mobile audio apps, which use audio commentary. This could be supplemented by commentary on the tour by the attractive tourist location.

Our results demonstrate that a potential app should feature a narrative, a possibility to upload additional information, as well as an interactive online map. The app might be offered at both App Store and Android Market Play free of charge with embedded in-app purchases 
(in that case, a price between 1 and 3 EUR might be appropriate).

The development of mobile applications for those interested in Jewish cultural heritage in Prague would, in our opinion, not only paid off in order to improve the quality of experience of foreign tourists visiting the Jewish monuments in the capital, but the application would also most likely contribute to the overall increase in the number of tourists in Prague since it could also work as a good promotional tool and a positive response among other potential visitors to Prague.

\section{References}

[1] Apple. (2013). Summary data. Press release summary data. Available at: http://images.apple.com/pr/pdf/q3fy13datasum. pdf

[2] Beeton, S. (2001). Smiling for the camera: the influence of film audiences on a budget tourism destination. Tourism, Culture and Communication, 3(1), 15-26. ISSN 1943-4146

[3] Beeton, S. (2004). Film Induced Tourism: Aspects of Tourism. Channel View Publicationsm, New York, NY

[4] Bendix, R. (1999). Cultural Tourism in Europe. Annals of Tourism Research,26(4), 1033-1034

[5] Bordoni, L. (2011). Technologies to support cultural tourism for Latin Latium.Journal of Hospitality and Tourism Technology, 2(2), 96-104

[6] Butler, R., O‘Gorman, K. D., \& Prentice, R. (2012). Destination appraisal for European cultural tourism to Iran. International Journal of Tourism Research,14(4), 323-338

[7] Carl, D., Kindon, S., \& Smith, K. (2007). Tourists' experiences of film locations: New Zealand as 'Middle-Earth. Tourism Geographies, 9(1), 49-63

[8] Chiabai, A., Platt, S., \& Strielkowski, W. (2014). Eliciting users' preferences for cultural heritage and tourism-related e-services: a tale of three European cities, Tourism Economics, 20(2), 263-277

[9] CZSO. (2013). Tourism statistics. Available at: http://www.czso. $\mathrm{cz} / \mathrm{csu} /$ redakce.nsf/i/cestovni_ruch

[10] CZSO. (2016). Tourism - time series. Available at: https://www. czso.cz/csu/czso/cru_ts

[11] Eriksson, N., \& Strandvik, P. (2008). Possible determinants affecting the use of mobile tourism services. In: International Conference on E-Business and Telecommunications, Springer Berlin Heidelberg, 61-73

[12] Eurostat (2016). Tourism statistics at regional level. Available at: http://ec.europa.eu/eurostat/statistics-explained/index. php/Tourism_statistics_at_regional_level

[13] Herget, J., Petrů, Z., \& Abrham, J. (2015). City branding and its economic impacts on tourism. Economics and Sociology, 8(1), 119-126

[14] Idel, M. (1990). Golem: Jewish magical and mystical traditions on the artificial anthropoid. SUNY Press, New York, NY
[15] Ihamäki, P. (2012). Geocachers: The creative tourism experience. Journal of hospitality and tourism technology, 3(3), 152-175

[16] Indrová, J., Houška, P., \& Petrů, Z. (2011). Kvalita ve službách cestovního ruchu. Oeconomica, Praha

[17] Jovicic, D. (2016). Cultural tourism in the context of relations between mass and alternative tourism. Current Issues in Tourism, 19(6), 605-612

[18] Kim, J. H., \& Ritchie, J. B. (2014). Cross-cultural validation of a memorable tourism experience scale (MTES). Journal of Travel Research, 53(3), 323-335

[19] Lamsfus, C., Wang, D., Alzua-Sorzabal, A., \& Xiang, Z. (2015). Going mobile defining context for on-the-go travelers. Journal of Travel Research, 54(6), 691-701

[20] Liu, Y., \& Li, H. (2011). Exploring the impact of use context on mobile hedonic services adoption: An empirical study on mobile gaming in China. Computers in Human Behavior, 27(2), 890-898

[21] MasterCard (2015). Global Destinations Cities Index. Available at: https://newsroom.mastercard.com/wp-content/ uploads/2015/06/MasterCard-GDCl-2015-Final-Report1.pdf

[22] Matoga, Ł., \& Pawłowska, A. (2016). Off-the-beaten-track tourism: a new trend in the tourism development in historical European cities. A case study of the city of Krakow, Poland. Current Issues in Tourism, 1-26

[23] Meyrink, G. (1915). Der Golem. Kurt Wolff, Leipzig

[24] Moura, F. T., Gnoth, J., \& Deans, K. R. (2014). Localizing cultural values on tourism destination websites: The effects on users' willingness to travel and destination image. Journal of Travel Research, 0047287514522873

[25] Rasinger, J., Fuchs, M., Beer, T., \& Höpken, W. (2009). Building a mobile tourist guide based on tourists' on-site information needs. Tourism Analysis,14(4), 483-502

[26] Richards, G. (1996). Production and consumption of European cultural tourism. Annals of tourism research, 23(2), 261-283

[27] Schwinger, W., Grün, C., Pröll, B., Retschitzegger, W., \& Werthner, H. (2006). Pinpointing Tourism Information onto Mobile Maps - A Light-Weight Approach.Information and Communication Technologies in Tourism 2006, 29-43

[28] Sever, N. S., Sever, G. N., \& Kuhzady, S. (2015). The Evaluation of Potentials of Gamification in Tourism Marketing Communication. International Journal of Academic Research in Business and Social Sciences, 5(10), 188-202

[29] Sherwin, Byron. (1985). The Golem legend: Origins and implications. University Press of America,. ISBN 081-914-402-9

[30] Strielkowski, W. (2012).Czech experience with using culture satellite account. Czech Journal of Social Sciences, Business and Economics, 1(1), 60-67

[31] Strielkowski, W. (2013). Mystery and thriller tourism: Novel solutions for European cities. Turizam: znanstveno-stručni časopis, (61)3, 277-287

[32] Strielkowski, W., Riganti, P., Wang, J. (2012). Tourism, cultural heritage and e-services: using focus groups to asses consumer preferences. Tourismos: an International Multidisciplinary Journal of Tourism, (7)1, 41-60

[33] Van Leeuwen, E. \& Nijkamp, P. (2010). A microsimilation model for e-services in cultural heritage tourism. Tourism Economics, (16)2, 361-384

[34] Vernon, J., Essex, S., Pinder, D., \& Curry, K. (2003). The 'greening' of tourism micro-businesses: outcomes of focus 
group investigations in South East Cornwall. Business strategy and the environment, (12)1, 49-69

[35] Wang, D., Xiang, Z., \& Fesenmaier, D. R. (2014). Adapting to the mobile world: A model of smartphone use. Annals of Tourism Research, 48, 11-26

[36] Wang, S., Yamada, N., \& Brothers, L. (2011). A case study: Discussion of factors and challenges for urban cultural tourism development. International Journal of Tourism Research, 13(6), 553-569

[37] Weidenfeld, A. (2013). Tourism and cross border regional innovation systems.Annals of Tourism Research, 42, 191-213

[38] Wisniewski, D. (1996), Golem, Clarion Books, New York, NY

\section{Appendix}

Questionnaire Jewish heritage in Prague

\section{Dear Sir/Madam,}

A group of researchers is conducting a research about the use of smartphone apps and e-services in presenting and enjoying Jewish heritage in Prague. The results of this questionnaire will be used solely for research purposes. Please help us and fill in the questionnaire. Thank you very much for your time!

1. Please tell us your country of residence:

2. Please tell us your age:

3. What is your gender: female male

4. How many nights are you staying in Prague?

5. Do you usually prepare for your trip by reading the reviews online, downloading itineraries, maps, guides, etc.? yes no

6. In case you answered "yes" in question 7, please tell us what exactly you download before your trip?

7. Do you own a smartphone? yes

no

8. Do you use your smartphone while travelling abroad to download maps, guides and other related apps? yes

no

9. If you answered "yes" in question 8, please tell us what kind of apps do you usually use?

10. How much are you usually willing to pay for such smartphone application?
11. Can you name some of the historic attractions associated with Jewish heritage that you have visited/plan to visit in Prague?

12. Do you use guided tours when visiting historic attractions and other landmarks? yes no

13. Please rate your satisfaction with the current way how the Jewish heritage is presented and offered in Prague on the Likert scale from 1 to 10 (1 being the worst and 10 being the best):

14. What aspect of the presentation of Jewish heritage would you improve?

Thank you for filling in our questionnaire! If you want to see the outcomes of this research, please leave us your e-mail address: 